\title{
Q La política interétnica de los ranqueles durante la segunda mitad del siglo XIX
}

\author{
Graciana Pérez Zavala ${ }^{1}$
}

\section{Introducción}

En la segunda mitad del siglo XIX salineros, ranqueles y manzaneros

Eeran las principales agrupaciones indígenas del área pampeana y norpatagónica². Los primeros, liderados por Calfucurá, se instalaron en las Salinas Grandes en la década de 1830 bajo el amparo de Juan Manuel de Rosas. Los ranqueles, en cambio, situados en la pampa central desde el siglo XVIII ${ }^{3}$, habían enfrenado a las expediciones del Gobernador porteño en pos de defender su autonomía. El cacique Chocorí también había sido afectado por las campañas punitivas de Rosas, logrando luego de ellas ser reconocido como un cacique de prestigio y sentar las bases para la conformación de una identidad manzanera que, liderada por Valentín Sayhueque, se destacó en los años '60 y '70 (Vezub 2002:170, Villar y Jiménez 2003:227-228).

Pese a algunas alianzas coyunturales cada uno de estos cacicatos tomó caminos estratégicos diferentes ante el afianzamiento del Estado argentino. Las rivalidades entre los caciques, las antiguas rencillas intraétnicas y las diferencias en la política de lucha para con los cris-

1 Becaria de CONICET. Departamento de Historia, Facultad de Ciencias Humanas, Universidad Nacional de Río Cuarto. E-mail: gracianapz@yahoo.com

2 Por motivos de espacio no se describen las distintas caracterizaciones y los procesos de etnogénesis de los indígenas de Pampa y Norpatagonia. Se sugiere la lectura de: Mandrini, 1984; Bechis 1998b, 1999, 2002; Nacuzzi, 1998; Gotta, 2002; Delrio, 2005; Tamagnini y Pérez Zavala, 2005a; Vezub; 2002; 2006; Jiménez, 2006; Varela y Manara, 2006; Villar y Jiménez, 2006.

3 De acuerdo a la documentación hacia la segunda mitad del siglo XVIII se habrían distinguido en las regiones del Mamul Mapu y Leu Mapu dos componentes indígenas que se denominaban ranqueles. Las variaciones entre éstos habrían estado dadas más bien por su adaptación a espacios ecológicos diferentes, que por sus rasgos socio-culturales. A lo largo de las primeras décadas del siglo XIX ambos grupos se habrían visto involucrados en complejos procesos de etnogénesis (Villar y Jiménez, 2006:2-6). 
tianos -a menudo estimuladas por las autoridades nacionales y los jefes fronterizos-, frustraron los intentos de unificación. Calfucurá y posteriormente sus hijos asumieron estrategias de alianza y de oposición según los acuerdos con los demás caciques de la región y con los gobiernos cristianos. Por su parte, los manzaneros jugaron su suerte en la estrategia de la "integración", en tanto Valentín Sayhueque se definió como "indio argentino" y justificó las campañas punitivas del Gobierno Nacional para con los salineros. Los ranqueles intensificaron los vínculos con el ejército y con el clero cordobés sin por ello perder su autonomía (M andrini y O rtelli 1993, Bechis 2002, Vezub 2002, Delrio 2005).

Desde la década de 1830 los ranqueles estuvieron representados por dos linajes independientes que co-gobernaban en el espacio pampeano, uniéndose en algunas ocasiones y separándose en otras ${ }^{4}$ (Bechis 1998b:185-186). U n linaje, emplazado en Lebucó, tuvo como caciques principales a Painé y a tres de sus hijos: Calbán, Mariano Rosas y Epumer. El otro, situado en Poitague, fue liderado por Yanquetruz y sus sucesores Pichún Guala, Yanquetruz Guzmán y Manuel Baigorria Guala (alias Baigorrita). Cada uno de estos linajes desplegó su propia estrategia política, visible en los malones y tratados de paz que se efectuaron en la segunda mitad del siglo XIX.

Desde una perspectiva que considera que el concepto de "política indígena" hace referencia tanto a la política cristiana "con respecto a los indígenas" como a la "política de los indígenas" (Villar y Jiménez 2003:198), este trabajo caracteriza la política impulsada por los ranqueles respecto al emergente Estado argentino durante la segunda mitad del siglo XIX. Específicamente, busca identificar y explicar las modificaciones y continuidades en el accionar político de los caciques según las distintas coyunturas que afectaron la formación de dicho Estado. El escrito plantea que durante las décadas de 1850 y 1860 los indígenas pudieron desplegar una variedad de estrategias y, por consiguiente, lograron posicionarse a nivel interétnico gracias a las posibilidades de alianza surgidas en el marco de las disputas entre las distintas facciones cristianas. En década de 1870, esta variedad de acción fue quedando coartada dado que el Gobierno N acional, convertido en el

4 Luego de la muerte de Yanquetruz (posiblemente en 1835) los ranqueles tuvieron, simultáneamente, dos caciques que actuaron como jefes de linaje y como principales. Si bien el cacicazgo de Yanquetruz debía recaer en su sobrino Painé y no en su hijo Pichún, tal como preveía una alianza matrimonial entre los linajes, en los hechos, las decisiones partieron del acuerdo de Painé y Pichún (Bechis, 1998b:185). 
único interlocutor frente al cual los ranqueles podían actuar, limitó la capacidad de movilidad indígena.

El trabajo está organizado en dos partes. En la primera caracteriza, someramente, la política indígena en pos de explicar a partir de ella el modo en que éstos hicieron frente a los cristianos. Luego, efectúa algunas aclaraciones metodológicas so bre los tratados de paz. Posteriormente describe las alianzas y contra alianzas surgidas en el período 1850-1880 entre los ranqueles, los salineros y las diferentes facciones cristianas.

El material documental que sustenta los argumentos de este escrito proviene de los Servicios H istóricos del Ejército (SHE), del Archivo $\mathrm{H}$ istórico de la Provincia de Córdoba (AHPC), del Archivo Histórico "Fray José Luis Padrós", Río Cuarto (AHCSF) y del Archivo Histórico Municipal de Río Cuarto (AHMRC).

\section{Algunas consideraciones sobre la política indígena}

Las relaciones entre indígenas y cristianos ocurridas en la Frontera Sur durante los siglos XVII, XVIII y XIX, estuvieron demarcadas por un conjunto de acciones que no se agotaron en las instancias de guerra y paz. En el marco de estas estrategias emergió la "política" como instancia "reflexiva" que posibilitó el establecimiento de vínculos entre sociedades que no podían aniquilarse mediante la violencia física. Así, la frontera y las tolderías estuvieron atravesadas por una compleja dinámica en la que las situaciones de conflicto interétnico se fueron resolviendo día a día, de acuerdo al contexto del momento. Dicho en otros términos, las relaciones interétnicas e intraétnicas variaban según los objetivos y las tácticas que implementaban jefes de frontera, misioneros, pobladores rurales, refugiados, caciques, capitanejos y lenguaraces. Algunas acciones, como la entrega de regalos y raciones, estuvieron ligadas al lenguaje de la generosidad y del parentesco e impulsaron el desarrollo de una "frontera mestiza". Otras, como los malones y las campañas punitivas, reavivaron las diferencias. Las múltiples conexiones entre indígenas y cristianos dieron lugar a políticas situacionales, basadas en relaciones "heterogéneas", "ambiguas" y "variables" (Mandrini 1993, Boccara 1996, Foerster y Vergara 1996, González Coll 2000, Roulet 2002, Ratto 2003, León y Villalobos 2004, Mandrini y O rtelli 2006). 
La política desplegada por los cristianos para con los indígenas fue modificándose según las coyunturas históricas y los grupos sociales que la impulsaban. Levaggi (2000) destaca que durante la segunda mitad del siglo XIX, dos antropologías diferentes tensaron por imponerse en el seno del Gobierno Nacional: una optimista (buscaba la incorporación del indígena por "medios pacíficos") y otra pesimista (impulsaba el sometimiento definitivo de los indígenas por medios violentos). Ambas legitimaron las campañas militares, los tratados de paz y los proyectos misionales que el Gobierno Nacional impulsó con respecto a los indígenas.

En términos generales, la aplicación de cada una de estas acciones encontraba su fundamento en la distinción entre indígenas amigos, aliados y enemigos. Los primeros eran aquellos que se mostraban dispuestos a colaborar de manera permanente con los cristianos y, en especial, que aceptaban perder su autonomía para vivir en campos "cedidos" por el Gobierno. Estos estaban bajo la autoridad de los jefes militares de la frontera y debían enfrentar a los indígenas enemigos si les era requerido. Los indios aliados eran aquellos que, a través de tratados con el Gobierno, mantenían su autonomía y territorios gracias a su compromiso de denunciar a los indígenas hostiles. Finalmente, los indígenas enemigos eran contrarios a las dos categorías indicadas, en tanto desplegaban una política de oposición a las fuerzas gubernamentales, por propia iniciativa como por alianzas con otras agrupaciones indígenas (Bechis 1998a, Ratto 1994, 2003, Villar y Jiménez 2006).

Estas categorías eran móviles. Una misma agrupación podía ser considerada enemiga, aliada o amiga según los acontecimientos históricos que demarcaban el accionar político de las partes. En este sentido, la política desplegada por los indígenas para con los cristianos respondía a metas económicas, sociales y políticas, tendientes todas a rechazar las presiones del Estado colonial o nacional pero, simultáneamente, obteniendo beneficios de éste. Asimismo, ciertos aspectos de la política indígena como su ductilidad y pragmatismo formaban parte de una concepción en la que el otro, el "enemigo", dejaba esa condición una vez que se había ganado la guerra o se había llegado a una alianza de paz. Para los indígenas "perder" significaba comenzar una negociación en la que se aceptaba la subordinación, se reorientaban las alianzas y, paradójicamente, se obtenían una serie de ventajas, expresadas en bienes cristianos (Vezub 2001, Roulet 2002, Delrio 2005). 
Bechis (1999) sostiene que la dinámica social de los indígenas del "área arauco-pampeana- norpatagónica" estaba sujeta a continuos procesos de fusión y fisión que involucraban a agrupaciones, caciques, capitanejos, mocetones y chinas. Esta flexibilidad repercutía en la lucha interétnica dado que, desde la perspectiva indígena, era posible modificar las alianzas ante beneficios coyunturales o de largo plazo. La política indígena, entonces, estaba sujeta a la relación pendular entre los cacicatos, la cual podía desarrollarse plenamente si el poder de decisión de cada capitanejo o cacique no era coartado y si existía un amplio abanico de posibilidades de negociación interétnica.

\section{Aclaraciones metodológicas}

Varias de las alianzas y contra alianzas surgidas entre indígenas y cristianos en el perío do examinado quedaron materializadas en tratados de paz. La problemática de los tratados no se agota en el documento que da cuenta de los compromisos asumidos por las partes. Lázaro Avila (1998:36-37) distingue entre las palabras "parlamentos", "juntas", "tratados" y "actas". Mientras las dos primeras refieren al conjunto de reuniones efectuadas entre cristianos e indígenas en torno a la concreción de acuerdos de paz, la palabra acta da cuenta del documento jurídico que materializa los tratados.

Estas diferencias se vinculan con el hecho de que en estos actos de conciliación convivía un derecho positivo -basado en la doctrina europea sobre los tratados que impulsaba la elaboración de un documento escrito refrendado y ratificado por los negociadores y las autoridades-, con otro consuetudinario -sostenido en la antigua institución indígena de las juntas en las que asistían los caciques, con sus capitanejos, mocetones y chusma-. Además, mientras para los cristianos la escritura tenía credibilidad, para los indígenas la oralidad era fuente de validez. Este último aspecto tiene connotaciones a nivel metodológico, en tanto la "pluma" de quien escribía no plasmó todas las palabras de quien hablaba. La asimetría de poder gestada en el proceso interétnico se hizo visible en el hecho de que lo acordado fue escrito en castellano, pese a que las sociedades pactantes hablaban lenguas diferentes y la lengua indígena no poseía escritura. Por esta razón, en este escrito se analizan las actas de paz teniendo en cuenta que la pluma "omite" acuerdos no oficiales, "oculta" parte de la discusión 
oral y "exalta" las jerarquías de los mediadores (Bechis 2000:9, Roulet 2004:313-314, 316; Pérez Zavala 2005:10-11).

Cuando se habla de tratados de paz es posible diferenciar dos situaciones: la primera es amplia y hace referencia a las instancias de negociación a través de las cuales cristianos e indígenas -reconociéndose como sociedades políticamente independientes-, buscaron solapar los conflictos no resueltos mediante la violencia física. La segunda alude a las formaciones documentales propiamente dichas que, bajo la forma de instrumentos jurídicos, expresan la relación de poder entre las sociedades pactantes.

Desde el punto de vista documental el primer aspecto quedó plasmado en cartas de variados remitentes, informes militares y sacerdotales y artículos periodísticos como también en bases o preliminares de tratado. Por su parte, las actas dan cuenta de la cristalización de la negociación y, según sus características, pueden ser clasificadas como oficiales, de negociación, originales y copias (Pérez Zavala 2004, 2005).

El examen unitario de las actas de los tratados realizados entre el Gobierno Nacional y los ranqueles en los años 1854, 1865, 1870, 1872 y 1878, muestra cómo paulatinamente los últimos fueron aceptando compromisos que limitaban su autonomía política y territorial. En cambio, la vasta documentación que acompaña las actas evidencia sobre los continuos procesos de resistencia indígena ante algunas cláusulas que comprometían su accionar político (Pérez Zavala 2005). El estudio conjunto de ambos documentos permite indagar sobre los puntos de discusión entre las partes y, en especial, posibilita distinguir la situación de fuerza de cada sociedad.

\section{Negociaciones cruzadas y simultáneas: Pichún, Calbán, Calfucurá, la Confederación Argentina y la Provincia de Buenos Aires en la década de $\mathbf{1 8 5 0}$}

La muerte de Painé en 1844 acentuó la separación entre los indígenas de Poitague y Lebucó. Pichún continuó siendo cacique general y de su linaje. A la vez que Calbán, el primer hijo del Painé, adquirió funciones de cacique de su linaje y de los ranqueles (Bechis 1998b). A lo largo de esa década y de la siguiente, ambos caciques buscaron posicionarse favorablemente dentro de su sociedad y ante los cristianos. 
El derrocamiento de Juan Manuel de Rosas en febrero de 1852 afectó los vínculos entre Pichún y Calbán que, por un lapso de dos años, desplegaron políticas opuestas. Tras el alejamiento de Rosas, el G eneral Justo José de U rquiza asumió el gobierno de todas las provincias del Río de la Plata. Este caudillo de extracción federal, se inclinó por la unificación nacional. Sin embargo, poco después, Buenos Aires, a través de sus representantes M itre y Alsina, se opuso a la política del entrerriano alegando que ésta afectaba los beneficios provenientes del control de la aduana. Estas disidencias se hicieron visibles en septiembre de 1852 cuando el panorama político presentaba por una parte a Buenos Aires y por otro lado a la Confederación Argentina, con sede en Paraná, que nucleaba al resto de las provincias.

Los fuertes fronterizos se convirtieron en espacios signados por las bruscas oscilaciones políticas. Los gobiernos de la Confederación y de Buenos Aires buscaron, entonces, sumar a sus filas a los indígenas, porque una alianza con éstos ofrecía seguridad a las fronteras y, simultáneamente, fuerzas auxiliares durante la guerra civil. Sin embargo, tal como lo destacan Bustos et al. (1994:21), el traslado de las contradicciones entre los cristianos al campo indígena a partir de la cooptación de las tribus, reforzó la capacidad de negociación de éstas gracias a la amenaza de acordar con el bando adversario.

La Confederación Argentina procuró acercarse a los indígenas enviando diversas comisiones de paz a las tolderías de los ranqueles y de Calfucurá. N arciso Corro fue destinado a las tolderías de los ranqueles en pos de atraer a la causa de U rquiza al refugiado Manuel Baigorria, que era un hombre clave para convencer a los indígenas. Baigorria aceptó la propuesta del nuevo Presidente y, a fines de agosto de 1852, regresó a la frontera. Fue reincorporado en el ejército, encargándosele organizar el Regimiento $\mathrm{N}$ o 7 de Caballería y llevar adelante las negociaciones de paz con los indígenas. Buenos Aires también intentó obtener la adhesión del refugiado unitario a través del General Paz, su antiguo jefe, pero la propuesta no surtió efecto. En su calidad de exrefugiado, Baigorria conocía el modo de actuar de los caciques y los mecanismos de negociación indígena, pudiendo tratar con éstos de igual a igual. Por ello, Baigorria, al unirse a las fuerzas de la Confederación, no sólo retiraba su apoyo a Buenos Aires, sino que le creaba a ésta otro enemigo (García Enciso 1979:80, Fernández 1998:183).

Con la misión de Baigorria se inició un proceso en el que la Confederación, Buenos Aires, los caciques ranqueles y Calfucurá, desple- 
garon diferentes acciones en pos de obtener el mayor rédito posible. M ientras las distintas facciones cristianas competían entre sí buscando la alianza con los indígenas, estos últimos implementaban diversas estrategias que les permitían sostener paralelamente relaciones con la Confederación y con Buenos Aires.

Las cartas de los militares cordobeses del período 1852-1854 condenan los malones de los indígenas de Calbán sobre la frontera de esa provincia, mientras que elogian el desempeño de Pichún, que impulsaba negociaciones de paz con la Confederación y, unido a Calfucurá, invadía el sur de Buenos Aires ${ }^{5}$. La documentación también permite advertir la política dual de Pichún. Este alegaba que "hoy en dia los hombres estamos muy bariables", razón por la cual impulsaba tratativas de paz con ambas facciones cristianas. En enero de 1854, el Coronel Cruz Gorordo se entrevistaba en Rojas con los emisarios de Pichún, mientras otra comitiva de este cacique partía para la Villa del Río Cuarto en pos de continuar las conversaciones de paz con la Confederación. Durante los meses de abril, junio y julio de 1854, tanto la Confederación como la provincia de Buenos Aires siguieron buscando, por diversos caminos, convencer a los indígenas de sus proposiciones. Según una carta del Coronel Baigorria de fines de junio, los caciques Pichún y Calfucurá recibían aguardiente de los jefes porteños $y$, especialmente, propuestas de compra de ganado. Por ello, para "no perder tiempo", el Coronel Manuel Baigorria enviaba nuevamente a su sobrino Antonino a las tolderías ${ }^{6}$.

El cacique de Salinas G randes, Calfucurá, también participó de las negociaciones de los ranqueles con el Gobierno de la Confederación. En los primeros meses de 1854, Pichún invitó a Calfucurá a sumarse al tratado que iba a efectuar con el Gobierno de la Confederación. Por tal motivo comisionó a su sobrino Yanquetruz, a su hijo Baigorrita y al Coronel Baigorria. Calfucurá aceptó la propuesta y envió a

5 AHPC. Indice de Gobierno 1811-1869. Año 1853. Tema: Comunicación a los indios. Tomo 232c. Legajo 1. Folio 3/4. Rte: Alejo Carmen Guzmán a Calbán. Córdoba, 23/03/1853; Folio 7. Rte: Alejo Carmen Guzmán a Manuel Baigorria. Córdoba, 23/03/1853.

6 AHPC. Gobierno. Año 1854. Tomo 239e. Legajo 6. Folio 148. Rte: Pichún Guala a Cruz Gorordo. Tierra Adentro, 22/01/1854; Folio 150: Rte: Cruz Gorordo a Pichún Guala. Pergamino, 28/01/1854; Folio 153: Rte: Manuel Baigorria a Alejo Carmen Guzmán. Río Cuarto, 12/02/1854; Folio 160: Rte: Manuel Baigorria a Alejo Carmen Guzmán. Río Cuarto, 17/03/1854; Folio 165: Rte: Manuel Baigorria a Alejo Carmen Guzmán. Río Cuarto, 24/06/1854. Comandancia General del Sur y Río Cuarto. Tomo 1. Folio 309: Rte: Alejo Carmen Guzmán a Juan B. Ferreyra. Córdoba, 29/01/1854. 
sus representantes a tratar con las auto ridades confederadas (Baigorria 1977:92). En esta coyuntura, el cacique Pichún emergió como figura política capaz de articular las relaciones interétnicas -gracias a su cercanía con el Coronel Baigorria- e intraétnicas, en tanto por su intermedio Calbán y Calfucurá logran pactar con la Confederación?

Entre julio y octubre de 1854 se sucedieron diferentes reuniones entre los comisionados de Pichún, Calbán y Calfucurá y el Gobernador de Córdoba, Alejo Carmen Guzmán, y entre los emisarios de éste y los caciques, que dieron por resultado la concreción de un tratado de paz. La comparación de la documentación generada en dichas entrevistas ${ }^{8}$ evidencia que la alianza interétnica se sustentó en el principio de que Pichún, Calbán y Calfucurá eran indígenas aliados a la Confederación, no quedando sujetos a ninguna fuerza cristiana9. De acuerdo al tratado, los caciques no podrían invadir las provincias confederadas ni realizar alianzas con los enemigos de éstas. Al mismo tiempo, el Gobierno de la Confederación se comprometía a no efectuar acuerdos con adversarios de los caciques firmantes. El tratado también testimonia sobre las alianzas intraétnicas. Pichún, Calbán y Calfucurá pactaron como unidad pero, simultáneamente, fueron reconocidos como máximas autoridades de las tribus que representaban, recibiendo análogos derechos y obligaciones. Este hecho da cuenta de la distancia entre los linajes ranqueles y, la de éstos y los salineros (Pérez Zavala 2003, Tamagnini y Pérez Zavala 2005a).

La alianza entre la Confederación, los ranqueles y Calfucurá demarcó el carácter de los vínculos entablados en los distintos tramos de la Frontera Sur. Mientras los poblados porteños debían hacer frente a constantes malones, los confederados hospedaban a las continuas comisiones indígenas que se acercaban hasta la frontera cordobesa para comerciar, buscar raciones o efectuar visitas protocolares. Pero, esta

7 AHPC. Indice de Gobierno 1811-1869. Año 1854. Tomo 239e. Legajo 4. Folio 88/89: Rte: No especificado (posiblemente Alejo Carmen Guzmán) a Calfucurá. Río Cuarto, 18/07/1854.

8 Estas reuniones quedaron plasmadas en cuatro preliminares de paz. AHPC. Indice de Gobierno 1811-1869. Año 1854. Tomo 239e. Legajo 4. Folio 95/96: Rte: Alejo Carmen Guzmán a Calbán, 1/08/1854; Folio 118. Rte: Pichún Guala a Alejo Carmen Guzmán, 10/09/1854; Folio 122/123/124: Rte: no especificado (posiblemente Alejo Carmen Guzmán) al Ministro de Guerra y Marina, Gral. Rudecindo Alvarado. Río Cuarto, 27/09/1854. Folio 127/128/129: Rte: Alejo Carmen Guzmán a Rudecindo Alvarado 11/10/1854.

9 Durante la negociación el Gobierno le propuso a los caciques trasladarse a la frontera para vivir en reducciones supervisadas por el Coronel Baigorria como también la secesión de sus “derechos territoriales". Pero los caciques rechazaron tales propuestas (Pérez Zavala, 2004). 
amistad entre la Confederación y los indígenas se desarrollaba en el marco de desconfianzas, tensiones y manipulaciones entre las partes, porque, en los años '50, la frontera de Córdoba fue uno de los escenarios en el que se proyectaban las divisiones políticas entre la Confederación y Buenos Aires. El conflicto interétnico estuvo signado por la tensión entre fuerzas fragmentadoras -que se oponían a la emergencia del Estado Nación- y unificadoras (Tamagnini 1999).

En 1855, Yanquetruz Guzmán sustituyó, transitoriamente, a Pichún. Por su parte, en 1858, M ariano Rosas reemplazó a Calbán, quien murió durante una explosión de piezas de artillería. Ello sucedió porque en 1857 el Gobernador de Buenos Aires, Pastor O bligado, envió al $\mathrm{G}$ ral. Emilio Mitre a las tolderías de los ranqueles con el fin de escarmentarlos. Las fuerzas porteñas se perdieron en el desierto, razón por la cual en cercanía de Italó dejaron la mayor parte de la artillería que los acompañaba. Poco después el cacique Calbán y algunos indígenas que lo acompañaban fueron víctimas de dichas armas (Zeballos 2001:63-74).

Frente a este ingreso de los porteños a las tierras indígenas, la posición del Gobierno de la Confederación fue de cautela. Este optó por no "tomar parte en disensiones de esa naturaleza ${ }^{10 "}$ ", pese a que por el tratado se había comprometido a prestar auxilio a los indígenas si éstos lo requerían. Por entonces, las disputas entre la Confederación y Buenos Aires se habían incrementado. A la guerra económica entre éstas se sumó una disputa política en la provincia de San Juan, que precipitó la ofensiva bélica e hizo que las dos facciones movilizaran sus ejércitos en Cepeda. El 23 de octubre de 1859 se enfrentaron, siendo el resultado favorable a la Confederación.

Según Zeballos (2001:110-111) la participación indígena en Cepeda fue importante. Los ranqueles se dividieron en dos grupos: uno, bajo las órdenes de Cristo y Coliqueo se incorporó a la división del Coronel Baigorria, que se retiró de la frontera cordobesa para unirse al ejército confederado. El otro grupo, liderado por los caciques Yanquetruz Guzmán, Epumer y Calfucurá maloqueó Buenos Aires. Mitre formó dos ejércitos con la ilusión de triunfar sobre ambos frentes, pero su plan fracasó.

10 AHPC. Gobierno. Año 1858. Tomo 4. Folio 334. Rte: Oficial $1^{\circ}$ a Felipe Salas, 13/02/1858. 
Luego de Cepeda y en el marco de la revolución liberal en Córdoba de $1860^{11}$, los compromisos del tratado de paz de 1854 se desdibujaron, al tiempo que comenzaron a tomar forma las alianzas intraétnicas e interétnicas que caracterizarían la década del '60. El tratado explicitaba que los ranqueles y Calfucurá debían ser leales a la Confederación y enemigos de Buenos Aires; pero cuando esta última dejó de ser independiente del resto de las provincias, el núcleo central del acuerdo quedó desvirtuado.

En octubre de 1860 la provincia de Buenos Aires juró la Constitución N acional. Pero, antes de finalizar el año la Legislatura bonaerense declaró nulo el Pacto de San José de Flores. Mientras tanto, Mitre preparaba su ejército y lograba la adhesión del Coronel Manuel Baigorria, que debía incorporársele "con quince oficiales, doscientos soldados cristianos y cuatrocientos indios aliados" (Terzaga 1976:100-102). En setiembre de 1861, Baigorria unió sus fuerzas a los mitristas, mientras el Gral. Juan Saá se dirigía hacia el litoral con la intención de sumarse a las tropas confederadas. La contienda entre los dos ejércitos ocurrió en Pavón el 17 de setiembre, con el triunfo de Buenos Aires.

La batalla de Pavón no solamente da cuenta del comienzo del período de Organización Nacional al que refiere la historiografía argentina; también atestigua el surgimiento de fragmentaciones entre los indígenas. Luego de ella, el cacique Coliqueo, que vivía entre los ranqueles, abandonó la Tierra Adentro para instalarse en tierras pertenecientes a la provincia de Buenos Aires (Barrionuevo Imposti, 1988:6069). Los ranqueles continuaron vinculados con los jefes de la disuelta Confederación, distanciándose de Calfucurá, que meses antes de la derrota confederada había pactado con Buenos Aires y, por tanto, adhería al nuevo Gobierno (Levaggi 2000:323-329).

\section{Uniones estratégicas y de resistencia: el Gobierno Nacional, las montoneras provinciales y los ranqueles en la década de 1860}

Después de Pavón la frontera cordobesa quedó desguarnecida porque las fuerzas comandadas por el Coronel Baigorria fueron en-

11 En marzo de 1860 Santiago Derqui asumió como Presidente constitucional del país unificado, pero el conflicto entre las provincias continuó. En Córdoba se produjo una "revolución interior", que buscó derrotar al gobierno de Fragueiro, de tinte liberal. En Río Cuarto, el ex Comandante Coronel Pedro Oyarzábal adhirió a la misma. El Coronel Baigorria defendió al gobierno depuesto, pero Derqui y Urquiza apoyaron a los sublevados. A Baigorria se le ordenó, entonces, ponerse bajo las órdenes del Gral. Juan Saá, su enemigo de tiempo atrás (García Enciso, 1979:81; Barrionuevo Imposti, 1988:61;69). 
viadas a Buenos Aires y luego a San Luis para participar de la persecución contra los federales. A ello se sumaron los reiterados malones de M ariano Rosas y Baigorrita sobre las estancias cercanas al río Cuarto, producto de la ruptura definitiva del tratado de paz de 1854. Estas invasiones se prolongaron hasta mayo de 1862 , fecha en que el cacique M ariano Rosas envió una propuesta de paz al Gobierno N acional. Las negociaciones fueron Ilevadas a cabo por el Coronel Baigorria. Sin embargo, ninguna parte confiaba en la otra: mientras los ranqueles maloqueaban, los jefes militares tomaban prisioneras a las comitivas que llegaban a la frontera. Inclusive, a fines de ese año los Coroneles Baigorria y Vedia efectuaron una campaña punitiva que se internó en los toldos ranqueles hasta las inmediaciones del Nahuel Mapu. Como respuesta a ella, desde marzo de 1863 fueron continuos los malones sobre la frontera cordobesa, a tal punto que las fuerzas nacionales debieron abandonar los fuertes de avanzada y replegar la línea militar en el río Cuarto (Barrionuevo Imposti 1988:84-92).

Por entonces, los vínculos entre las montoneras y los indígenas eran importantes y se manifestaban en una variedad de situaciones que iban desde el estallido simultáneo de ambas fuerzas sociales, sobre distintos puntos de la frontera, hasta la recepción de desertores, cabecillas y miembros de la montonera en las tolderías. Así, por ejemplo, en 1863, los ranqueles prestaron su apoyo a Juan Gregorio Puebla, uno de los líderes locales de la montonera del Chacho Peñaloza, que actuaba sobre las fronteras cordobesa y puntana. Luego de la derrota del Chacho, este cabecilla se refugió en las tolderías para regresar después a la frontera al frente de un importante contingente ranquel que actuó sobre Villa Mercedes (Tamagnini y Pérez Zavala 2003).

La guerra con Paraguay obligó al Gobierno Nacional a pactar con los indígenas. Ello era necesario, por un lado, porque importantes sectores regionales, representados por Felipe Varela, Juan Saá y López Jordán, proclamaban un programa en contra de dicha guerra y de la centralización económico-política que se estaba desarrollando desde Buenos Aires. Por otro, porque las fuerzas militares de la frontera debían marchar a la guerra internacional ${ }^{12}$. Luego de dos meses de negociaciones, el General Emilio Mitre y su comisionado, el Coronel Manuel Baigorria, llegaron a un acuerdo con los caciques ranqueles.

12 AHPC. Diario "El Eco de Córdoba”. 14/05/1865. Epoca 2. Año 5. № 718. Tomo 7. pp. 2. 
Estos pactaron en forma separada: Baigorrita aceptó su tratado el 18 de junio de 1865 y Mariano Rosas hizo lo mismo el día $22^{13}$.

Para esta fecha la República Argentina era la única entidad política real, en tanto la Confederación había desaparecido y su resabio, las montoneras provinciales, actuaban en un marco de subordinación. Por ello, en las actas de 1865 primaba la idea del Gobierno Nacional de controlar y codificar las relaciones sociales imperantes en la frontera y en la Tierra Adentro. En este sentido, uno de los puntos del tratado estipulaba que M ariano Rosas y Baigorrita considerarían como enemigo a Calfucurá y a las "otras indiadas". Esta cláusula encontraba sus fundamentos en los mal ones que por entonces efectuaba Calfucurá sobre los poblados cordobeses ${ }^{14}$.

La variación en el accionar de los ranqueles con respecto de los salineros puede ser inscripta dentro de la dinámica socio-política indígena, en donde eran frecuentes tanto las asociaciones como los distanciamientos entre agrupaciones. Sin embargo, en esta coyuntura -en la que el Gobierno Nacional se estaba convirtiendo en el único interlocutor interétnico-, tal disparidad de movimientos habría contribuido a posicionar a ranqueles y salineros en campos opuestos. El siguiente relato de un jefe de frontera testimonia este aspecto:

"acaban de llegar unos indios de la toldería del cacique Baigorria (Manuel Baigorria Guala o Baigorrita, ahijado del Coronel Manuel Baigorria) y con ello me manda a avisar que se prepara una invasión a las fronteras por la indiada de Calfucurá, la que tendrá lugar en esta línea; y que tanto él como el cacique Mariano Rosas, están dispuestos a privarles el paso toda vez que toque por sus inmediaciones o por lo menos dar parte inmediatamente"15.

Los tratados de 1865 también afectaban los vínculos entre ranqueles y montoneras. Algunos artículos otorgaban un rol destacado a los caciques, debiendo éstos controlar y castigar a indígenas y refugiados que no avalaran la política del Gobierno Nacional. Los caciques no

13 SHE. Año 1865. Campaña contra los indios. Doc. No 820 y 821.

14 AHPC. Indice de Gobierno 1811-1869. Año 1865. Tomo 4, Comandancia del Río Cuarto (y de los del Sud). Folio No 600. Rte: Cnel. Antonino Baigorria al Ministro General del Gobierno, José Antonio Alvarez de Condarco. Fecha: 15/08/1865. Río Cuarto; Folio 604. Rte: Antonino Baigorria a Mariano Echenique. Río Cuarto, 15/09/1865.

15 AHMRC, Diario "La Calle", Río Cuarto. 29/07/1955. Tomo 9. pp. 3. Rte: Emilio Mitre a José Iseas. Río Cuarto, 17/06/1865. En: Rodríguez, 1955. 
desconocían los efectos futuros de estos puntos por lo que buscaron evitar tales compromisos, solicitando al Gral. Emilio Mitre su modificación. Gestionaron así el indulto de "todos los cristianos aliados en los toldos por delitos de carácter político"16.

Los tratados de paz tuvieron vigencia sólo unos meses. Baigorrita rompió su pacto en agosto de 1865 mientras que Mariano Rosas lo hizo un mes después ${ }^{17}$. Finalizados éstos, la "alianza" entre los ranqueles y las montoneras se reavivó. Los jefes de las fronteras de Córdoba y San Luis debieron enfrentar tanto las invasiones indígenas como las sublevaciones de las montoneras. En 1866, el despliegue combinado de estas dos fuerzas sociales adquirió toda su magnitud ${ }^{18}$. En noviembre comenzó en Mendoza la "revolución de los Colorados", que contó con la participación de los hermanos Saá. Simultáneamente, el 22 de noviembre de 1866, 500 ranqueles protagonizaron una "gran invasión" que llegó hasta el corral de Barrancas (5 leguas al Norte de Río Cuarto). Las fuerzas nacionales que los persiguieron, lograron apoderarse de 10.000 cabezas y de 70 cautivos (W alther, 1980:284). Este fue el último gran malón que arremetió en cercanías de la Villa del Río Cuarto, de modo que el mismo condensa tanto el poderío de los ranqueles como su debilitamiento.

D urante los primeros meses de 1867 los malones continuaron sobre el sur de Córdoba, San Luis y M endoza e incluso algunos ranqueles participaron en los combates guiados por los Saá ${ }^{19}$. Sin embargo, el 1 ㅇ de abril, los federales se enfrentaron con las fuerzas lideradas por el General Arredondo, en el sitio de San Ignacio (San Luis). Allí, Ios Colorados fueron derrotados. Algunos de sus jefes marcharon hacia Chile, mientras que otros se internaron en la Tierra Adentro. Simultáneamente a la desorganización de las montoneras que actuaban en el sur de Córdoba y San Luis, el Congreso Nacional procuraba resolver

16 AHMRC. Diario "La Calle", Río Cuarto. 29/07/1955. Tomo 9. pp. 3. Rte: Emilio Mitre a Gelly y Obes. Río Cuarto, 30/06/1865. En: Rodríguez, 1955. AHPC. Diario "El Eco de Córdoba". 3/08/1865. Epoca 2. Año 5. N 785 . Tomo 8. pp. 1. Rte: Emilio Mitre a Roque Ferreyra. Río Cuarto, 29/06/1865.

17 AHMRC. Diario "La Calle", Río Cuarto. 30/07/1955. Tomo 9. pp.3. Rte: Manuel Baigorria a Benito Nazar. 28/08/1865. Rte: Manuel Baigorria a Julián Martínez. 28/10/1865. En: Rodríguez, 1955.

18 Durante el año 1866, sólo en el sur de la provincia de Córdoba, se produjeron 11 malones (Barrionuevo Imposti, 1988:119-123; Walther, 1980:283-330).

19 AHMRC. Diario “La Calle”, Río Cuarto. 18/08/1955. Tomo 9. pp. 3. Rte: Calfucurá a Barros. Salinas Grandes, 28/02/1867. En: Rodríguez, 1955. 
el "problema indígena", sancionando la ley $N^{\circ} 215$ relativa al avance de la frontera hasta los ríos Negro y Neuquén (Barrionuevo Imposti, 1988:122-129; Fernández, 1998:192). Ante esta nueva coyuntura, la alianza característica de la década de 1860 (ranqueles-montoneras contra el Gobierno Nacional) comenzó a debilitarse.

\section{Alianzas impuestas: el Gobierno Nacional y los indígenas en la década de 1870}

En los comienzos de la década de 1870 las relaciones entre los ranqueles y el Gobierno Nacional seguían siendo conflictivas, sin embargo, el panorama político había cambiado en detrimento de los indígenas. La guerra con el Paraguay estaba finalizando, los núcleos de las montoneras que aún actuaban en el litoral estaban siendo controlados y los jefes militares avanzaban poco a poco hacia el sur -en 1869 la línea militar del río Cuarto fue trasladada al río Quinto-. En el marco de estos acontecimientos, los caciques ranqueles impulsaron y sostuvieron negociaciones de paz con el Gobierno Nacional, dejando atrás la política de interactuar simultáneamente con otras fuerzas cristianas.

En enero de 1870 el Coronel Mansilla, como representante del Gobierno Nacional, concretó un tratado de paz con los caciques Mariano Rosas, Manuel Baigorrita, Epumer, Ramón y Yanquetruz. Este no fue aprobado por el Congreso Nacional pero fue discutido en las tolderías de los ranqueles durante la excursión del citado militar ${ }^{20}$.

El acta de 1870 testimonia la asimetría de poder en las relaciones interétnicas. Un artículo afirmaba que el tratado quedaría sin efecto "a la primera invasion grande ó chica de las tribus de Mariano Rosas y Baigorria y demás que les esten subordinados", pero ninguna cláusula aclaraba que éste caducaría si el Gobierno Nacional realizaba una campaña punitiva sobre las tolderías. A su vez, otro artículo estipulaba que Mariano Rosas y Baigorrita se comprometían a "empuñar las armas en defensa de la República", en caso de "invasión extranjera". A diferencia de los tratados de 1854 y 1865, los beneficios de esta alianza eran unilaterales: Ios ranqueles eran obligados a colaborar con el Gobierno Nacional, pero no serían retribuidos en forma similar en

20 SHE. Campaña contra los indios. Doc. $N^{\circ} 1084$. Tratado de paz de 1870. Este documento es una copia de un acta de negociación. Durante la presencia de Mansilla en las tolderías se habría aprobado el texto final del tratado, que no ha sido localizado. 
situaciones de conflictos intraétnicos. Asimismo, los ranqueles se comprometían a "someter a las tribus indígenas que rompieran sus pactos con el Gobierno Nacional". En este sentido, uno de los objetivos de M ansilla durante su visita a las tolderías fue lograr la adhesión de los ranqueles para "someter a Calfucurá"21.

Este tratado tiene la particularidad de haber sido efectuado por los ranqueles, en tanto unidad política. En esta ocasión, Mariano Rosas firmó en representación suya y del cacique Baigorrita. Sin embargo, este acuerdo entre los dos linajes ranqueles no se sostuvo en el tiempo. En diciembre, cuando el tratado había caducado, los caciques Mariano Rosas y Manuel Baigorrita desplegaron estrategias de lucha diferentes: mientras el primero impulsaba negociaciones de paz, el segundo maloqueaba junto a Calfucurá (Tamagnini y Pérez Zavala, 2002).

En 1871, el franciscano Donati22 afirmaba:

"muy poco duró el tratado de Mansilla [...] Sin embargo continué á procurar que los Yndios se mantuviesen en paz. Para eso escribí á Mariano, al Cacique Ramon diciéndoles; que el Gobierno habia triunfado sobre las montoneras, habia triunfado sobre el Paraguay y en Entre Rios, y que los Yndios no se considerasen mas fuertes que estos, debian esperar sino se mantuviesen en paz una inevitable guerra. Asi como le anuncié, á la letra se verificó" 23 .

Según Jorge Fernández (1998:195-197) la campaña sobre las tolderías de los ranqueles de Antonino Baigorria en 1871, la llegada a la frontera del río Cuarto del General Roca y de los efectivos que combatieron en la guerra del Paraguay en 1872, fueron el ementos que propiciaron el debilitamiento de los ranqueles. La primera, porque mostró el poderío cristiano, el segundo, porque generó nuevos proyectos y los últimos, porque trajeron consigo la conciencia de sometimiento

21 Carta de Mansilla a Arredondo. 3/1870. En: Levaggi, 2000:409.

22 En 1855 la legislatura cordobesa avaló la instalación de misioneros franciscanos en la Villa de la Concepción del Río Cuarto para que impulsaran la "pacificación" de los ranqueles. En noviembre de 1856 llegaron los religiosos al Convento de Río Cuarto, pero recién en 1868 dicho Convento adquirió la categoría de "Colegio Apostólico de Propaganda Fide". Fray Marcos Donati fue designado como Prefecto de Misiones y desde entonces efectuó ofrecimientos a los principales caciques ranqueles para que se redujeran. Los mismos rechazaron las propuestas aún cuando mantuvieron una fluida comunicación con los sacerdotes. A su vez, los franciscanos conformaron dos reducciones sobre la línea del río Quinto Sarmiento y Villa Mercedes con capitanejos ranqueles que abandonaron las tolderías por la fuerza $(1872 ; 1877)$ y en forma voluntaria (1874; 1875) (Tamagnini y Pérez Zavala, 2005b).

23 AHCSF. Crónica de Quírico Porreca. Epoca II. Año 1882-1889. Capítulo 17, pp. 219 -220. 
a la autoridad nacional. A estos motivos debe agregarse el mejoramiento de las comunicaciones entre los jefes militares, a partir de la instalación de telégrafos en los fuertes de avanzada y de la llegada del ferrocarril a la frontera del río Cuarto. Finalmente, la batalla de San Carlos (mayo de 1872) ${ }^{24}$ que significó, además del fracaso militar indígena, su derrota social y política. Social, porque la contienda fue entre indígenas que optaban por defender su autonomía e indígenas que adherían al proyecto nacional. Política, porque después de esta batalla los primeros debieron aceptar ciertas imposiciones del Gobierno Nacional.

U na de las primeras medidas de Calfucurá luego de San Carlos fue solicitar la concreción de un tratado de paz, enviando emisarios al General Ignacio Rivas y al Coronel Julián M urga. Los jefes de frontera recibieron las comitivas pero por entonces tenían instrucciones de avanzar sobre las tolderías (Levaggi, 2000:440-441).

Los ranqueles también pidieron la paz y, al igual que Calfucurá, debieron hacer frente a la negativa nacional. En mayo de 1872, el General Arredondo quemó las tolderías de Lebucó. Luego de cinco meses de intensas negociaciones los ranqueles efectuaron un nuevo tratado con el Gobierno. Este fue ratificado por M ariano Rosas, Baigorrita, Epumer Rosas y Yanquetruz ${ }^{25}$ y, a diferencia de 1870, cada cacique avaló personalmente los compromisos y beneficios de la paz.

Durante las tratativas, Mariano renegaba de las cláusulas de la paz mientras Baigorrita las impulsaba. Esta diferencia en la política

24 En 1872 el cacique Calfucurá había convocado a las indiadas de Pampa, Patagonia y Chile para hacer frente al Gobierno Nacional ante el desarrollo de una nueva expedición en la isla Choele-Choel a cargo del almirante Martín Guerrico. Para contrarrestar este avance, Calfucurá encabezó un gran malón sobre 25 de Mayo, fuerte de avanzada de la Provincia de Buenos Aires. En un primer momento, los indígenas lograron su objetivo, escapando con gran cantidad de ganado y cautivos. Sin embargo, en San Carlos, los indígenas debieron presentar batalla a los efectivos nacionales liderados por el Gral. Rivas. Estos eran numéricamente inferiores y contaban entre sus filas a 800 lanceros de Catriel y 150 de Coliqueo, muchos de los cuales estaban en estado de rebeldía. Pese a esta situación, las fuerzas nacionales lograron desmembrar a las de Calfucurá y recuperar gran parte del botín (Poggi, 1998; Zeballos, 2001).

25 Sobre este tratado se poseen varias actas las cuales se localizan en los siguientes Archivos: SHE. Año 1872. Campaña contra los Indios. Doc. $N^{\circ} 1188$ (copia de acta oficial), AEZ. Carpeta indios (acta original en poder de los ranqueles hasta 1878, fecha en que fue entregada a Estanislao Zeballos). En: Durán, 2006:184; AEF. Año 1872. Sección VIII. 79 (1). Doc. № 811 (acta de negociación original) y AHCSF. Año 1872. Doc. No 256 (copia de acta de negociación). Estos documentos remiten a distintos momentos de la negociación, por ello en algunos artículos se observan diferencias notorias en lo estipulado. Para un análisis detallado véase Pérez Zavala, 2003, 2005. 
desarrollada por los caciques puede analizarse teniendo en cuenta dos aspectos. En primer lugar, ambos conocían los planes del Gobierno de avanzar sobre sus territorios y, por tanto, buscaban lograr el mejor acuerdo posible. La oposición entre los caciques formaba parte de la política indígena de posicionamiento interétnico. En segundo lugar, no se puede olvidar el impacto de las políticas nacionales en el interior de la sociedad indígena, que incentivaban las rivalidades entre los caciques (Tamagnini y Pérez Zavala, 2002).

Por su parte, la mayor diferencia entre el tratado de 1872 y su antecesor radica en que los ranqueles fueron definidos como "miembros de la República Argentina". El encabezamiento del acta de paz establece que los caciques admitían "la soberanía y la autoridad de la nación". Este tratado nuevamente comprometía a los ranqueles a colaborar en las guerras en que la República Argentina pudiera verse involucrada, "en cuyo caso el Gobierno Nacional les daría Armas, pago y alimentos". Por esta cláusula los indígenas, potencialmente, formaban parte de los ejércitos de línea. D urante las tratativas, el cacique M ariano Rosas se opuso a este compromiso aduciendo que

"no me conviene y no quiero tomar partido en sus cuestiones yo a lo que me comprometo es a no ayudar ni desayudar, yo solo quiero vivir en paz si por ejemplo sucede que se vean en guerra entre unitarios o federales, de todo me desentiendo"26.

La respuesta del cacique evidencia por un lado, el deterioro de la política indígena de negociar con múltiples interlocutores y, por otro, el quiebre de la alianza entre ranqueles y montoneras. En los años siguientes, Mariano Rosas llevó adelante su política de no inmiscuirse en los conflictos de los cristianos. Por ejemplo, en 1873, recibió ofrecimientos de los Saá de adherir a los focos de resistencia federal que estaban actuando en Entre Ríos, pero optó por mantenerse en paz con el Gobierno Nacional. Asimismo, los jefes de frontera trataron de disuadir a los indígenas de participar en tales levantamientos, recordándoles que "pronto vendrán los cuerpos de Entre Ríos a sus respectivas

26 SHE. Campaña contra los indios. Doc. N ${ }^{\circ}$ 1188. Tratado de paz de 1872. AHCSF. Año 1872. Doc. N ${ }^{o}$ 257. Rte: Mariano Rosas a Marcos Donati. Lebucó, 25/10/1872. En: Tamagnini, 1995:9-10. 
fronteras, pues la guerra aquella está ya terminada. Lopez Jordán ha sido completamente destruido"27.

Durante la revolución mitrista de $1874^{28}$, el jefe de la frontera de Córdoba, San Luis y M endoza, el General Arredondo adhirió a los sublevados convirtiendo al fuerte de Villa Mercedes en base de las operaciones. El Gobierno Nacional temió por la actitud de los ranqueles, de modo que buscó neutralizarlos enviando a las tolderías las raciones atrasadas y, en especial, recordándoles "que ahora mas que nunca deben conservar la Paz que la nación con motivo de la revelion de Rivas y Arredondo tiene un poderoso ejercito con numerosas caballadas". Durante la revolución del '74 los ranqueles se mantuvieron leales al Gobierno N acional ${ }^{29}$.

Entre 1872 y 1878, más allá de las demoras y la baja calidad de los productos, el Gobierno Nacional cumplió con la entrega de las raciones acordadas a los caciques porque la paz con los ranqueles era estratégica. Esta permitía desdoblar las fuerzas de Namuncurá, mientras el Ministro de Guerra y Marina desplegaba su plan de avance sobre la frontera de Buenos Aires. En el marco de los últimos acontecimientos, en diciembre de 1875, Baigorrita se plegó a los malones que efectuaban los indígenas de Juan José Catriel, Namuncurá y Pincén en contra de la "zanja de Alsina". Con estas acciones, Baigorrita rompió el tratado de paz de $1872^{30}$. Sin embargo, M ariano Rosas permaneció leal al Gobierno e inclusive impulsó a Baigorrita a reanudar el tratado de paz. Ello se concretó en marzo de 1876 (Levaggi, 2000:519). En este proceso los caciques que querían sostener la paz con el Gobierno debían enfrentarse a sus pares. Las diferencias entre Mariano y Baigorrita se acentuaron a tal punto que el primer cacique, a fines de 1876,

27 AHCSF. Año 1873. Doc. N 292. Rte: Mariano Rosas a Miguel Arredondo. Lebucó, 15/03/1873; Doc. N $^{\circ}$ 374. Rte: Julio A. Roca a Marcos Donati. Río Cuarto, 14/012/1873. En: Tamagnini, 1995:14.

28 En 1873 Mitre y Avellaneda fueron candidatos a la presidencia. En las elecciones ganó el segundo, pero Mitre se opuso encabezando una revolución que tuvo por propósito derrocar al presidente electo.

29 AHCSF. Año 1874. Doc. No 468. Telegrama. Julio A. Roca a Marcos Donati. Villa Mercedes, 26/10/1874; Doc. No 1160b: Relación de Moisés Alvarez. 8/06/1880. En: Tamagnini, 1995:303.

30 AHCSF. Año 1876. Doc. No 603: Rte: Moisés Alvarez a Marcos Donati. Sarmiento, 2/0271876; Doc. N $^{\circ}$ 607: Rte: Mariano Rosas a Marcos Donati. Lebucó, 16/02/1876. En Tamagnini, 1995: 206-207; 32. 
denunciaba los malones que planificaban Baigorrita, Pincén y $\mathrm{N}$ amuncurá sobre la campaña bonaerense ${ }^{31}$.

En Agosto de 1877 falleció M ariano Rosas, siendo reemplazado por su hermano Epumer. El nuevo cacique y Baigorrita continuaron respaldando el tratado de 1872 mediante el envío de comisiones a la frontera. Sin embargo, como decía el padre Alvarez, los indígenas se valían de la astucia para no quedar bajo las órdenes del Gobierno $\mathrm{N}$ acional ${ }^{32}$. Ambos caciques permitían a sus indígenas maloquear en algunos puntos de la línea militar de avanzada y luego, cuando los jefes militares los incriminaban, deslindaban su responsabilidad culpabilizando a los indios gauchos ${ }^{33}$. Los jefes militares utilizaban en su favor estas invasiones, en tanto les servían de excusa para hacer "corridas" sobre las tolderías y, en especial, para obligar a los indígenas a reducirse. Este fue el caso del sometimiento del cacique Ramón Cabral, quién, en octubre de 1877, debió hacer frente a una comisión militar que le apresó sus animales aduciendo que eran robados. El cacique los reclamó pero, el Coronel Racedo le impuso, como base para la entrega del ganado, trasladarse a la frontera ${ }^{34}$.

Los indígenas no desconocían los planes del Gobierno Nacional -en julio de 1878, Baigorrita le confiaba al Padre Donati: "dicen algunos jefes que me ban a Inbadir"35, motivo por el cual las distintas tribus de Pampa y Patagonia se reunían en parlamentos, en pos de acordar la formación de un frente común ante la ofensiva cristiana. Los

31 AHCSF, Año 1876. Doc. No 618 y Doc. № 694. Rte: Moisés Alvarez a Marcos Donati. Sarmiento, 28/05/1876; 3/12/1876. En: Tamagnini, 1995.

32 AHCSF. Año 1877. Doc. No 738: Rte: Moisés Alvarez a Marcos Donati. Sarmiento, 4/06/1877; Doc. No 729: Rte: Epumer Rosas a Marcos Donati. Lebucó, 17/04/1877; Doc. No 719b: Rte: Marcos Donati a Moisés Alvarez. Villa Merced, 21/02/1877. En: Tamagnini, 1995:228; 37; 73.

33 En la documentación son frecuentes las menciones a los "indios gauchos". Mansilla (1933:111) ejemplifica esta categoría con el indio Blanco indicando éste era "un indio sin ley ni sujeción a nadie, a ningún cacique mayor, ni menos a ningún capitanejo". Mariano Rosas refiere a este tipo de indígenas cuando informa sobre malones efectuados sin su consentimiento (Tamagnini, 1995:4). Las actas de 1870, 1872 y 1878 establecían que los indígenas que transitaran en la frontera sin la "licencia" de su cacique serían considerados "Indios gauchos", pudiendo ser tratados por las autoridades "como ladrones".

34 Memoria del Departamento de Justicia, Culto é Instrucción Pública correspondiente al año 1877, presentada al Honorable Congreso Nacional en 1878, Buenos Aires, Anexo B, Misiones, pp. 357-358

35 AHCSF. Año 1878. Doc. No 893. Rte: Manuel Baigorria a Marcos Donati. Poitague, 3/07/1878. En: Tamagnini, 1995:46. 
ranqueles, escucharon tales propuestas, pero optaron por renovar los compromisos de paz de $1872^{36}$. El nuevo tratado, además de impedir que los ranqueles se aliaran con los grupos opuestos al G obierno $\mathrm{Na}$ cional, condicionaba las estrategias políticas de caciques, capitanejos e indios gauchos, en tanto obligaba a los caciques a denunciar los movimientos de las "tribus enemigas" del Gobierno y de los "indios ladrones". Poco después de su firma, los jefes de la frontera cordobesa denunciaban que los indios gauchos no habían cumplido con lo pactado. Bajo este justificativo iniciaron las expediciones militares hacia las tolderías de los ranqueles.

\section{A modo de cierre}

El presente trabajo examinó algunos acontecimientos que se sucedieron en la Frontera Sur, provincia de Córdoba, durante la segunda mitad del siglo XIX con el fin de dar cuenta de la dinámica política desplegada por indígenas y cristianos. Específicamente, consideró el accionar de los ranqueles teniendo en cuenta la relación entre los linajes de Lebucó y Poitague; los lazos de ambos linajes con los salineros y los vínculos entre tales agrupaciones y las distintas formaciones cristianas.

A lo largo de las décadas de 1850, 1860 y 1870, ranqueles, salineros, porteños, confederados y montoneras, desplegaron un vasto conjunto de alianzas y contra alianzas que permiten caracterizar como zigzagueante a la política desplegada por cada uno de estos grupos en tensión. Los malones, las sublevaciones, las campañas punitivas, los tratados de paz, la recepción de refugiados en las tolderías, los regalos y las intrigas, fueron algunas de las estrategias más destacadas en este proceso de posicionamiento interétnico e intraétnico. Esquemáticamente, y teniendo en cuenta las alianzas de largo plazo, pueden diferenciarse tres etapas en este conflictivo proceso, que llevó progresivamente al deterioro de la capacidad de acción política de los indígenas ante el fortalecimiento y unificación de la política nacional.

Los sucesos de la década del '50, dan cuenta del amplio marco de acción que tuvieron los indígenas, cuando la Confederación Argentina y la provincia de Buenos Aires confrontaban entre sí. El dispar accionar de los caciques Pichún y Calbán entre 1852-1854, deja al

36 SHE. Año 1878. Campaña contra los Indios. Doc. N ${ }^{\circ}$ 1346. En: Walther (1980:579-581). 
descubierto el modo en que los indígenas desplegaron una política de lucha que desconcertaba a los cristianos. Porteños y confederados agasajaban al cacique que mostraba interés en aliarse $y$, al mismo tiempo, hacían frente a los malones que efectuaba el jefe enemigo. En este proceso, Calfucurá se sumó a este "doble juego" de los caciques ranqueles, actuando en consonancia con éstos. El tratado de paz de 1854 cristalizó la alianza entre la Confederación Argentina, los caciques ranqueles y Calfucurá hasta 1861. La primera respaldó su palabra de paz entregando obsequios y raciones a los indígenas, a la vez que éstos maloquearon en la provincia de Buenos Aires y colaboraron durante la batalla de Cepeda (1859).

La alianza de 1854, que delimitó los vínculos interétnicos e intraétnicos de los años ' 50 , se modificó notablemente ante la emergencia de un Gobierno N acional unificado. Desde entonces, comenzó un proceso en el que las diferencias entre cristianos tendieron a "disolverse" (en gran medida a través de acciones violentas), mientras que se acentuaron la de los indígenas. En la década de 1860 la guerra fue constante, expresando tanto la política interétnica como intraétnica. La escasa duración de los tratados de 1865, entre el Gobierno N acional y los caciques Mariano Rosas y Baigorrita, pone de manifiesto la conflictividad del período. Asimismo, dichos tratados muestran como el equilibro de poder entre indígenas y cristianos había comenzado a romperse en favor de los últimos. El progresivo sometimiento de las montoneras provinciales por parte del Gobierno Nacional, fue restringiendo las posibilidades de acción de los indígenas de presionar sobre varios frentes a la vez. Además, la política nacional, tendió a posicionar en campos opuestos a ranqueles y salineros, reavivando las diferencias entre éstos.

Durante la década del '70, el Gobierno Nacional continuó coartando los movimientos indígenas. Los caciques ya no podían maloquear sobre una provincia y pactar con otra en forma paralela, como tampoco podían ser aliados del Gobierno y, simultáneamente, de los grupos cristianos y de las tribus opositoras a éste. A estas restricciones en el campo de la acción política, se sumaron expediciones militares sobre las tolderías $(1871,1872)$ y derrotas en los malones efectuados en la provincia de Buenos Aires. En estas condiciones, en 1872, los caciques Mariano Rosas y Baigorrita concretaron un tratado que tuvo vigencia hasta 1878. La "paz" que sostuvo este tratado formó parte de una política de sometimiento, que actuó sobre aquellos que no acep- 
taban ser parte de la "República Argentina". Este proceso trajo consigo la acentuación de las rivalidades en el campo indígena y, como contrapartida, la eliminación de las diferencias en la sociedad cristiana.

\section{Bibliografía}

BAIG O RRIA, Manuel (1977) Memorias del Coronel Manuel Baigorria, Buenos Aires, Eudeba.

BARRIONUEVO IMPOSTI, Víctor (1988) Historia de Río Cuarto. Constitucionalismo y liberalismo nacional, Tomo III, Buenos Aires, Impresión Carlos Firpo S.R.L.

BECHIS, Martha (1998a) "Fuerzas indígenas en la política criolla del siglo XIX", en: GOLDMAN, N. y R. SALVATORE (comp.) Caudillos rioplatenses. Nuevas miradas a un viejo problema, Buenos Aires, Eudeba, pp. 293-318.

_- (1998b) "Repensando la sucesión Yanquetruz-Paine-Calban: una contribución a la destrivialización de la historia ranquelina", en: Memorias de las Jornadas Ranquelinas, Santa Rosa, Instituto Nacional de Asuntos Indígenas, Gobierno de la Provincia de La Pampa, pp. 181-193.

- - (1999) "Los lideratos políticos en el área araucano-pampeana en el siglo XIX: ¿autoridad o poder?" en: Etnohistoria, CD Rom del Equipo NayA.

- - (2000) "Valor y validez de documentos generados o refrendados por los aborígenes soberanos de las Pampas y Norpatagonia", en Revista Educación y Humanidades, № 9, Temuco, Ediciones de la U niversidad de la Frontera, pp. 5-26.

- - (2002) "La Organización Nacional y las tribus pampeanas durante el siglo XIX", en: Pueblos, comunidades y municipios frente a los proyectos modernizadores en América Latina, siglo XIX, Holanda, Universidad de Lieven, Méjico, Colegio de San Luis, pp. 83-105.

BOCCARA, Guillermo (1996) "Dispositivos de poder en la sociedad colonial fronteriza chilena del siglo XVI al siglo XVIII", en: PINTO RODRÍGUEZ, J. (ed.) Del discurso colonial al proindigenismo, Temuco, U niversidad de la Frontera, pp. 27-40. 
BUSTOS, Jorge; GONZÁLEZ, Stella Maris y Antonia PERONJA (1994) "Los tratados de paz como una de las manifestaciones de las relaciones interétnicas. El tratado con Yanquetruz, 1857", en: Revista de la Escuela de Antropología, № 3, Rosario, U niversidad Nacional de Rosario, pp. 17-27.

DELRIO, Walter (2005) Memorias de expropiación. Sometimiento e incorporación indígena en la Patagonia. 1872-1943, Buenos Aires, Universidad Nacional de Quilmes.

DU RAN, Juan (2006) N amuncurá y Zeballos. El Archivo del cacicazgo de Salinas Grandes (1870-1880), Buenos Aires, Bouquet editores.

FERN ÁN D EZ, Jorge (1998) H istoria de los indios ranqueles. O rígenes, elevación y caída del cacicazgo ranquelino en la pampa central (siglos XVIII y XIX), Buenos Aires, Instituto N acional de Antropología y Pensamiento Latinoamericano.

FOERSTER, Rolf y Jorge VERGARA (1996) "¿Relaciones interétnicas o relaciones fronterizas?", en: Excerpta $\mathrm{N} \cong$ 5, http://www.uchile. cl/facultades/csocial es/excerpta/.

GARCÍA ENCISO, Carlos (1979) "Situación de la Frontera Sur con los indios. 1852-1873", en: Epopeya del desierto en el sur argentino, Vol. № 698, Buenos Aires, Círculo Militar.

GONZÁLEZ COLL, María Mercedes (2000) La vida en la Frontera Sur. Relaciones interétnicas y diversidad cultural, Bahía Blanca, Universidad Nacional del Sur.

GOTTA, Claudia (2002) "El papel de la guerra en la génesis y consolidación de la jefatura de Sayhueque". En: AU STRAL, A y A. M. RO CCHIETTI (comp.) Segundas Jornadas de Arqueología H istórica y de Contacto del Centro O este de la Argentina y Seminario de Etnohistoria. Terceras Jornadas de Arqueología y Etnohistoria del Centro Oeste del País, Río Cuarto, Universidad Nacional de Río Cuarto, pp. 79-93.

JIM ENEZ, Juan Francisco (2006) Llanketruz. El sitio de un "corsario", en: MANDRINI, R. (editor) Vivir entre dos mundos. Las fronteras del sur de la Argentina. Siglo XVIII y XIX, Buenos Aires, Nueva Dimensión Argentina, Taurus, pp. 73-94.

LÁZARO AVILA, Carlos (1998) "Parlamentos de paz en la Araucanía y las pampas: una visión comparativa (1620-1820)", en: Memoria 
Americana. Cuadernos de Etnohistoria, № 7, Buenos Aires, U BA, pp. 29-60.

LEÓN, Leonardo y Sergio VILLALOBOS (2004) "Tipos humanos y espacios de sociabilidad en la frontera de Argentina y Chile, 1800-1900", en: LEÓN, L. HERRERA, P. PARENTINI, L. C. y S. VILLALO BOS Araucanía: La Frontera Mestiza, Siglo XIX. Santiago de Chile, Ediciones U CSH, Lom ediciones, pp. 23-62.

LEVAG GI, Alberto (2000) Paz en la frontera. Historia de las relaciones diplomáticas con las comunidades indígenas en la Argentina (Siglos XVI-XIX), Buenos Aires, U niversidad del M useo Social Argentino.

M ANDRINI, Raúl (1984) Los araucanos de las pampas en el siglo XIX, Buenos Aires, Centro Editor de América Latina.

- - (1993) "Guerra y paz en la frontera bonaerense durante el siglo XVIII", en Ciencia Hoy, Vol. 4, № 23, marzo-abril, Buenos Aires, pp. 26-35.

MANDRINI, Raúl y Sara ORTELLI (1993) Volver al país de los araucanos, Buenos Aires, Sudamericana.

- - (2006) "Las fronteras del sur", en: MANDRINI, R. (ed.) Vivir entre dos mundos. Las fronteras del sur de la Argentina. Siglo XVIII y XIX, Buenos Aires, Nueva dimensión Argentina, Taurus, pp. 21-42.

M AN SILLA, Lucio (1993) U na excursión a los indios ranqueles, Tomo I, Buenos Aires, Compañía Editora Espasa Calpe Argentina S. A.

NACUZZI, Lidia (1998) Identidades impuestas. Tehuelches, aucas y pampas en el norte de la Patagonia, Buenos Aires, Sociedad Argentina de Antropología.

PÉREZ ZAVALA, Graciana (2003) "Tratados de paz en la frontera del río Cuarto: características documentales y negociación política", en: Jornadas de Investigación, Río Cuarto, Facultad de Ciencias Humanas, Universidad Nacional de Río Cuarto, CD.

- (2004) Relaciones interétnicas en la frontera del río Cuarto. Un análisis a partir de los tratados de paz entre el Gobierno Nacional y las tribus ranqueles (1852-1880). Trabajo Final de Licenciatura, Río Cuarto, Universidad N acional de Río Cuarto.

- - (2005) "Oralidad y escritura: los tratados de paz entre el Estado argentino y las tribus ranqueles", en: Revista Tefros, Vol. 3. № 1, Taller de Etnohistoria de la Frontera Sur. 
PO G GI, R (1998) Frontera Sur, 1872, M onografías N , Buenos Aires, Fundación Nuestra Historia.

RATTO, Silvia (1994) "Indios amigos e indios aliados. Orígenes del "Negocio Pacífico" en la Provincia de Buenos Aires (1829-1832)", en: Cuadernos del Instituto Ravignani 5, Buenos Aires, Facultad de Filosofía y Letras, UBA.

- (2003) ¿Soberanos, clientes o vecinos? Algunas consideraciones sobre la condición de los indígenas en la sociedad bonaerense, en: VILLAR, D. (ed.) Conflicto, Poder y Justicia en la frontera bonaerense. 1818-1832, Bahía Blanca, Santa Rosa, Universidad Nacional del Sur; U niversidad N acional de La Pampa, pp. 9-42.

RODRÍGUEZ, Juan Carlos (1955) "Historia Militar de la Villa del Río Cuarto", en: Diario "La Calle", Río Cuarto.

ROULET, Florencia (2002) "Guerra y diplomacia en la frontera de Mendoza: la política indígena del Comandante José Francisco de Amigorena", en: NACUZZI, L. (comp.) Funcionarios, diplomáticos y guerreros. Miradas hacia el otro en las fronteras de Pampa y Patagonia (siglos XVIII y XIX), Buenos Aires, Publicaciones SAA, pp. 65-118.

- (2004) "Con la pluma y la palabra. El lado oscuro de las negociaciones de paz entre españoles e indígenas", en: Revista de Indias, Vol. LXIV, № 231, Dossier: Indios, ciencia y política. Argentina, siglo XVIII-XIX. Dpto. de Historia de América "Fernández de Oviedo". Instituto de Historia, mayo-agosto, pp. 313-348.

TAM AGN INI, M arcela (1995) Cartas de Frontera. Los documentos del conflicto interétnico, Río Cuarto, Universidad Nacional de Río Cuarto.

—_(1999) "Fragmentación, equilibrio político y relaciones interétnicas (1851-1862). La Frontera del Río Cuarto", en: TAMAGNINI, M. (comp.) Segundas Jornadas de investigadores en arqueología y etnohistoria del centro-oeste del país, Río Cuarto, Universidad Nacional de Río Cuarto, pp. 199-209.

TAMAGNINI, Marcela y Graciana PÉREZ ZAVALA (2002) "El debilitamiento de los ranqueles: el tratado de paz de 1872 y los conflictos intraétnicos", en: NACUZZI, L. (comp.) Funcionarios, diplomáticos y guerreros. Miradas hacia el otro en las fronteras 
de Pampa y Patagonia (siglos XVIII y XIX), Buenos Aires, SAA, pp. 119-157.

_- (2003) "Yendo y viniendo de aquí para allá": al gunas características del accionar combinado de indígenas y montoneras en la Frontera Sur (Provincia de Córdoba) durante la década de 1860", en: V Encuentro Argentino-Chileno de estudios históricos e integración cultural, San Juan, U niversidad N acional de San Juan, CD.

- - (2005a) "Los tratados de paz de la segunda mitad del siglo XIX y el estudio de las tribus ranqueles", en: Actas de X Jornadas Interescuelas/Departamentos de Historia, Rosario, Universidad $\mathrm{Nac}$. del Litoral; Universidad Nac. de Rosario. CD.

_- (2005b) "Políticas colonizadoras en la frontera del río Quinto: las reducciones franciscanas (1854-1880)", en: VI Congreso internacional de Etnohistoria, Buenos Aires, UBA. CD.

TERZAGA, Alfredo (1976) Historia de Roca. De soldado federal a Presidente de la República, T. I. Buenos Aires, Biblioteca de Estudios Americanos, Peña Lillo Editor.

VARELA, Gladys y Carla MANARA (2006) "Feliciano Purrán. El señor de los Andes", en: MANDRINI, R. (ed.) Vivir entre dos mundos. Las fronteras del sur de la Argentina. Siglo XVIII y XIX, Buenos Aires, Taurus, pp. 259-288.

VEZUB, Julio (2001) "El álbum de fotografías de los ingenieros Encina y M oreno: la mirada etnográfica de los topógrafos durante la 'Conquista del Desierto'", en: VIII Jornadas Interescuelas / Departamentos de Historia, U niversidad $\mathrm{N}$ acional de Salta.

- - (2002) "La 'secretaría de Valentín Sayhueque'. Correspondencia indígena, poder e identidad en el país de las manzanas (18601883)", en: Estudios Trasandinos. Revista de la Asociación ChilenoArgentina de Estudios Históricos e Integración Cultural. № 7, Primer semestre, Santiago, U niversidad de Valparaíso; U niversidad de Santiago de Chile, pp. 159-179.

VEZU B, Julio (2006) Don Valentín Sayhueque. EL Gobernador indígena de las Manzanas, en: MANDRINI, R. (ed.) Vivir entre dos mundos. Las fronteras del sur de la Argentina. Siglo XVIII y XIX, Buenos Aires, Taurus, pp. 289-318. 
VILLAR, Daniel y Juan Francisco JIMENEZ (2003) "Conflicto, poder y justicia. El cacique M artín Toriano en la cordillera y las pampas (1818-1832)", en: VILLAR, D. (ed.) Conflicto, Poder y Justicia en la frontera bonaerense. 1818-1832, Bahía Blanca \& Santa Rosa, D pto. de H umanidades, U niversidad N acional del Sur; Facultad de Ciencias Humanas, Universidad Nacional de La Pampa, pp. 131228.

(2006) "Acerca de los ranqueles. Los indígenas del Mamil Mapu y del Leu Mapu (1750-1840)", en: Primer encuentro entre Investigadores y Pueblos Originarios del Centro de Argentina, Santa Rosa, U niversidad Nacional de La Pampa.

W ALTHER, Juan Carlos (1980) La Conquista del Desierto, Buenos Aires, Eudeba.

ZEBALLOS, Estanislao (2001) Callvucura, Paine y Relmu, Buenos Aires, El Elefante Blanco.

\section{Resumen}

En el marco de los estudios sobre la Frontera Sur, este trabajo caracteriza la política que desplegaron los ranqueles respecto al emergente Estado argentino durante la segunda mitad del siglo XIX. Específicamente, busca identificar y explicar los cambios y las continuidades en el accionar político de los principales caciques ranqueles según las distintas coyunturas que afectaron la formación del Estado argentino. El escrito plantea que durante la década de 1870 la relación entre indígenas y cristianos se habría tornado plenamente asimétrica, en razón de que por entonces el Gobierno Nacional argentino había logrado convertirse en el único interlocutor frente al cual los ranqueles podían actuar. Para sustentar este argumento, el texto describe las alianzas y contra alianzas surgidas en el período 1850-1880 entre los ranqueles y las diferentes facciones cristianas, en tanto ellas muestran cómo a medida que el Estado argentino iba imponiéndose sobre los grupos opositores a su emergencia, los indígenas veían deteriorada su capacidad de actuación política. Así, primero, examina los sucesos de la década del '50 por cuanto dan cuenta del amplio marco de acción que tuvieron los indígenas, cuando la Confederación Argentina y la Provincia de Buenos Aires confrontaban entre sí. Luego, analiza los acontecimientos de los años '60 en los que los ranqueles unieron sus 
fuerzas a los sectores federales opuestos al liderazgo de Buenos Aires. Finalmente, estudia las acciones indígenas en los años previos a su sometimiento.

Palabras claves: Ranqueles, Estado argentino, Política indígena, tratados de paz, alianzas.

\section{Rankeles' interethnic policies during the second half of the 19th century \\ Summary}

In the context of studies concerning the Southern Frontier, this paper wants to characterise the policy that ranqueles developed towards the emerging Argentinian State during the second half of the 19th century. Specifically, it attempts to identify and explain the changes and continuities in the political actions from the main ranqueles chiefs according to the different drawbacks that affected the creation of the Argentinian State. In this sense, the work states that during the 1870's the relationship between indigenous and cristianos had turned into an assimetrical one, due to the fact that the National Government from that period had succeeded in turning into the unique interlocutor with which the ranqueles could act. To support this statement, the text describes the alliances and counteralliances that appeared in the period 1850-1880 between the ranqueles and the different cristianos sectors, since they demonstrate that as the Argentinian State was imposing over the opposition groups to its formation, the indigenous faced deterioration of their capacity of political action. In this way, it examines first the events from the 50's as they give account of the great role that the indigenous played when the Argentine Confederation and the Province of Buenos Aires were confronting. Later, it analyses the events from the 60 's when the ranqueles joined their forces to the federal groups in opposition to the leadership of Buenos Aires. Finally, it studies the indigenous actions prior to their subjugation.

Key words: Ranqueles, Argentinian State, indigenous policy, peace treaty, alliances.

Recibido: 23/10/06, aceptado: 06/02/07. 